\title{
THE HUMAN DEVELOPMENT INDEX: SOME TECHNICAL ISSUES AND ALTERNATIVE INDICES
}

\author{
FARHAD NOORBAKHSH* \\ Centre for Development Studies, University of Glasgow, UK
}

\begin{abstract}
This paper examines the components and structure of the UNDP's Human Development Index and briefly reviews the criticisms of this index in the literature. It suggests some improvements on the components of the index as well as proposing a different structure for the index itself. These result in a set of alternative indices, based on the same components, for measuring human development. Data from the Human Development Report 1995 are used to test and compare the robustness of all the measures discussed. Furthermore it attempts to establish whether the developed indices based on the components of the HDI have the expected properties of an index or whether they are 'redundant' as proposed by some literature. (C) 1998 John Wiley \& Sons, Ltd.
\end{abstract}

\section{INTRODUCTION}

For more than four decades the adequacy of gross national product as a measure of the welfare of a society has been questioned. As early as 1954 a report by the United Nations on social policy and planning regarded economic growth as a requirement for better living standards rather than the ultimate policy aim (UN, 1954).

In 1969 experts on social policy and planning warned that 'The fact that [economic] development either leaves behind, or in some ways even creates, large areas of poverty, stagnation, marginality, and actual exclusion from economic and social progress is too obvious and too urgent to be overlooked' (UN, 1969, p. 5). Nearly a decade later a group of prominent scholars suspected that '... the economic growth by itself may not solve or even alleviate the problem [of poverty] in any reasonable time period' (Ahluwalia in Chenery et al., 1976, p. 1). Some suggested that development should be seen as '... creating the conditions for realisation of human potentiality' (Seers, 1972). Others argued for a change in the objectives of development programmes and

\footnotetext{
* Correspondence to: Farhad Noorbakhsh, Centre for Development Studies, University of Glasgow, Glasgow G12 8RT, UK. e-mail: f.noorbakhsh@socsci.gla.ac.uk 
proposed the satisfaction of basic needs as a replacement for purely macroeconomic objectives (Hicks and Streeten, 1979; Streeten et al., 1981) thus attempting to move the emphasis towards human objectives. ${ }^{1}$ The most important deficiency of the traditional development economics was regarded to be its "concentration on national product, aggregate income and total supply of particular goods rather than on entitlements of people and the capabilities these entitlements generate' (Sen, 1984, p. 496).

Such concerns resulted in searching for alternative measures of human welfare (development). ${ }^{2}$ The most recent attempt in constructing a measure of human development is the annual publication of the human development index (HDI) by the UNDP which has been used for ranking countries since 1990. This index has been favoured on the grounds that it shows the inadequacy of other indices such as GNP (Streeten, 1994; 1995). ${ }^{3}$ It has been preferred to per capita income as the latter neglects the distributional aspects (Desai, 1993) and it has been suggested that it 'captures many aspects of human development' (Haq, 1995, p. 54).

This paper, after a brief examination of the HDI, considers some of its criticisms in the literature and takes them into account in constructing four modified indices. It uses the most recent data from the UNDP for examining the robustness of these indices and compares the results. It also attempts to investigate the validity of some of the criticisms in the case of the HDI and other indices.

\section{THE COMPONENTS AND STRUCTURE OF THE HDI}

The HDI is a composite index of four indicators. Its components are to reflect three major dimensions of human development: longevity, knowledge and access to resources. These are to represent three of the essential choices 'for people to lead a long and healthy life, to acquire knowledge and to have access to resources needed for a decent standard of living' (HDR, 1990).

These dimensions are derived from the notion of human capabilities as proposed by Amartya Sen and are regarded to be the essential requirements for enhancing human capabilities (Desai, 1993). As such 'the process of economic [human] development can be seen as a process of expanding the capabilities of people' (Sen, 1984, p. 497). While it may be argued that there are other dimensions which could equally be regarded as essential, such as law and order, peace, security and freedom, it has been suggested that the components of the HDI together seem to provide an almost acceptable package of indicators of the level of living at an aggregate level (Dasgupta and Weale, 1992).

The dimension of longevity is directly measured by life expectancy at birth. Knowledge is presented by a measure of educational achievement based on a

\footnotetext{
${ }^{1}$ The debate on the concept of development, however, continued. For example, see Sen (1988; 1990); Streeten (1994); Srinivasan (1994); and Haq (1995).

2 Amongst the early attempts we may refer to the levels of living index (Drewnowski and Scott, 1966) and development index (McGranahan et al., 1972). Another measure, developed later, excluded the income component altogether. The physical quality of life index (PQLI) had three social components: infant mortality rate, life expectancy and adult literacy (Morris, 1979). For one such attempt in the 1980s see McGranahan et al. (1985).

${ }^{3}$ For Streeten (1995) see the introductory chapter in Haq (1995).
} 
weighted sum of adult literacy rate $(2 / 3)$ and the combined first, second and third level gross enrolment ratio (1/3).

Access to Resources is represented by the real per capita income, purchasing power parity in dollar (PPP\$), of countries adjusted with reference to its average global value $\left(y^{*}\right)$. This was done by employing the Atkinson formulation for the utility of income $W(y)$ :

$$
W(y)=\left(\frac{1}{1-\varepsilon}\right) y^{1-\varepsilon}
$$

where $1-\varepsilon$ is the elasticity of the utility of income.

Since 1994 the HDI for country $i$ was computed from the following formula:

$$
\mathrm{HDI}_{i}=\frac{1}{3} \sum_{j=1}^{3}\left(\frac{X_{i j}-\min F_{j}}{\max F_{j}-\min F_{j}}\right)
$$

where $X_{i j}$ is the actual value of component $j$ for country $i$ and $\min F_{j}$ and $\max F_{j}$ are the minimum and maximum values, fixed subjectively, for four constituent indicators.

\section{A CRITICAL REVIEW OF THE HDI}

The HDI has been criticized on the grounds of harshly curtailing income above a selected threshold and thereby not considering the income differentials, for those countries with relatively high incomes, adequately. This does not seem to be in line with the proposition that higher income would widen people's choice (TraboldNubler, 1991). It has also been suggested that there is no reason why the principles of diminishing returns would not be applicable to different components of the index (Kelly, 1991).

The HDI can be sensitive to the selected fixed ranges ( $\min F_{j}$ and $\max F_{j}$ ) for its components. The UNDP argues that these fixed 'normative' values have been selected as the extreme values observed or expected over a long period. It may be argued that the expectations of the value of an indicator over a long period is very likely to be a subjective estimate. It may also be said that there are ranges of values for both $\min F_{j}$ and $\max F_{j}$ which may be equally acceptable on the same grounds. However, depending on the selected extreme values the results would be different for each component.

The problem is that as HDI is the average of the sum of three equally weighted indices, it follows that the absolute value of each component will affect the level of HDI. Hence the selected extreme values would affect the value of the index resulting in a change in the ranking order (Noorbakhsh, 1996a).

In general the simple addition of the components HDI has just little justification. ${ }^{4}$ To put the argument differently, as the three components of HDI are spread around different means with different variances, the simple averaging of these components for the purpose of building a composite index would be questionable. In addition the means and variances of different components would vary with respect to the selected extreme values for $F_{j}$.

\footnotetext{
${ }^{4}$ Hopkins (1991) goes further by stating that there is no a priori rationale for the simple addition of the components of HDI as they represent different concepts.
} 
Furthermore, the HDI has been criticized on the grounds of attaching equal weights to its components (Kelly, 1991). More importantly it has been suggested that it produces the same ranking results as some of its components. It is, therefore, concluded that it would reveal 'few additional insights into intercountry development levels and, as such, can be viewed as redundant' (McGillivray, 1991, p. 1462).

\section{A MODIFIED HUMAN DEVELOPMENT INDEX (MHDI)}

Noorbakhsh (1996a) suggests a modified human development index which takes into account some of the criticisms mentioned above. Namely by allowing a wider range for $\varepsilon$ it allows for wider variations in the income component of the index (see Table A1 in Appendix A). It also applies the principle of diminishing returns to the educational components (see Table A2 in Appendix A). As for the structure of the index itself MHDI removes the scale effect by standardizing the data first. The standardized components would then constitute three vectors in a multi-dimensional vector space. Conceptually this makes sense as any index for human development should be defined within the context of all countries. It is possible to demonstrate that the length of these vectors are equal (Noorbakhsh, 1996a).

These vectors of equal length can constitute the axes of the space. Countries may then be presented as vectors in this space. In effect in the standardized data matrix, where rows and columns are the countries and components respectively, the vector space consists of the row vectors and the matrix columns are a co-ordinate system for this space. The distance between any two such vectors may then be measured by the length of the so-called distance vector.

We can be concerned with the distance vector between country $i$ and the country with the maximum standardized score for individual components (the country with the ideal score). Keeping to the same number of components the distance vector $d_{i}$ for country $i$ will have three components. The length of the distance vector from the best country(ies) for country $i$ is then measured by:

$$
d_{i}=\left(\sum_{j=1}^{3}\left(Z_{i j}-Z_{0 j}\right)^{2}\right)^{1 / 2}
$$

where $Z_{0 j}$ is the standardized score on component $j$ for the ideal country. ${ }^{5}$ The lower the $d_{i}$ the better the position of country $i$. In order to make this index comparable with the UNDP's HDI the above measure may be reversed and expressed in percentile terms to result in a modified human development index (MHDI), as follows:

$$
\mathrm{MHDI}_{i}=1-\frac{d_{i}}{\bar{d}+2 s_{d}}
$$

where $\bar{d}$ and $s_{d}$ are the mean and standard deviations of distances for all countries from the ideal country. The second expression on the right-hand side of equation (4) reflects the expectation that 95 per cent of cases are between the mean and two standard deviation of the distribution. ${ }^{6}$

\footnotetext{
${ }^{5}$ See Noorbakhsh (1996a) for further details.

${ }^{6}$ In practice a few countries fell outside the range of $0-1$, as expected. In order to include them within the range we used mean plus 2.2 standard deviation in equation (4).
} 
The data from 1995 HDR was used for computing the suggested adjusted components and the MHDI. The results are presented in Table A3 in Appendix A along with the results of other indices developed below.

\section{THE MHDI WITH WEIGHTED COMPONENTS}

The HDI has been criticized on the grounds of attaching equal weights to its selected components. Some researchers have argued that as an increase in income can increase people's choice and achieve improvements on other components, it should be given a higher weight (Kelly, 1991).

Strictly speaking components of HDI do not carry equal weights. We mentioned before that the choice of $\max F_{j}$ and $\min F_{j}$ would result in different scaling of the components. As the index is the average of these differently scaled components in effect it would attach various weights to the components. This unintentional weighting, however, does not provide an answer to the criticism of equal weighting of components. On the contrary it questions the validity of the HDI.

The standardization of the selected components in the MHDI would get rid of the problem of unintentional weighting. However, the question of equal weighting of the components may be still raised in the case of the MHDI.

An a priori determination of weights for various components implies the existence of a universally acceptable human welfare/development function which is not the case. An alternative way is to derive these weights from the data. As there is no firm agreement on the definition of human development and therefore not directly observable we are essentially dealing with a hypothetical construct. In this sense the human development construct is comparable with other constructs such as that of intelligence in psychology. These are both complex constructs initially based on a set of relevant variables whose structures may be assessed and explained in terms of a smaller number of latent vectors. In this sense it would be possible to derive a set of weights from the latent roots (eigenvalues) and latent vectors (eigenvectors) of the data matrix.

The application of principal components analysis (PCA) would reduce the data matrix to its latent vectors (factors) each accounting for a proportion of the total variance. The combination of correlations between components and factors (factor loadings) and the proportion of variance explained by the factors may be used for deriving a set of weights to be associated with the components. Factor analysis has been employed for similar purposes (for example, see Adelman and Morris, 1967; and Noorbakhsh, 1976) and its use for the specific purpose mentioned above has been recommended (for example, see Desai, 1993; and Srinivasan, 1994). The application of the principal component analysis has also been noted by the UNDP (HDR, 1993). ${ }^{7}$

The application of PCA resulted in three factors presented in Table 1.

It is interesting to note that all three components of MHDI - the adjusted educational attainment (AEA), the adjusted real GDP per capita in PPP\$ (AGDP) and the life expectancy (LE) - have very high loadings on factor 1. This factor with an

\footnotetext{
${ }^{7}$ In the HDR 1993 a reference is made to a study by H. Tatlidil (1992) 'A new approach for human development: human development scores'. Sussex: Institute of Development Studies (IDS), (mimeo). In response to my query the librarian of the IDS has informed me that there is no trace of this document or the name of the author in their records. However, the results are discussed in the HDR (1993).
} 
Table 1. Factor loadings for the components of MHDI.

\begin{tabular}{lccc}
\hline Components/Factors & Factor 1 & Factor 2 & Factor 3 \\
\hline LE & 0.962 & -0.024 & -0.272 \\
AEA & 0.905 & -0.394 & 0.159 \\
AGDP & 0.895 & 0.425 & 0.132 \\
Eigenvalue & 2.55 & 0.34 & 0.12 \\
$\mathrm{Vt} \%$ & 84.9 & 11.2 & 3.9 \\
$\mathrm{CVt} \%$ & 84.9 & 96.1 & 100 \\
\hline
\end{tabular}

eigenvalue of 2.55 accounts for almost 85 per cent of the total variance $(V t)$ while the remaining two factors with eigenvalues of 0.34 and 0.12 account for around 11 per cent and nearly 4 per cent of the total variance respectively.

The loadings themselves are the correlations between the components and factors. All components have high correlations with factor 1 resulting in rather high coefficients of determination between them and factor 1 . In effect 93 per cent of variations in LE are in common with, and can be explained by, factor 1 . The respective figures for AEA and AGDP are 82 and 80 per cent. The high loadings of these components on factor 1 suggest that the equal weighting of the components is not very inappropriate. In a way this factor may be interpreted as the factor of human development as explained by our three components. As factor 1 accounts for a very high proportion of total variance it is possible to argue that it is by far the most dominant factor. It is then possible to compute the so-called factor scores for all countries on the basis of this dominant factor. The application of equations (3) and (4) to these scores resulted in a weighted index which we called MHDIF $1 .{ }^{8}$

Alternatively we may consider the first two factors in developing another index as together they account for more than 96 per cent of the total variance. However, it should be noted that the negative coefficient of AEA next to the positive coefficient of AGDP on factor 2 add to the difficulties of interpreting this factor.

We computed the factor scores for the first two factors for all countries. The computed factor scores were then standardized and weighted by their contributions to the total variance. Equation (3) is not anymore suitable for finding the distance vector as we have two sets of factor scores with different weights. Instead we can use the following equation for finding the weighted distances:

$$
d_{i}=\left(\sum_{p=1}^{2}\left(S_{i p}-S_{0 p}\right)^{2} w_{p}\right)^{1 / 2}
$$

where $S_{i p}$ is the standardized factor score for country $i$ on factor $p, S_{0 p}$ is the ideal standardized factor score for factor $p$ and $w_{p}$ is the weight derived from the proportion of total variance accounted for by factor $p .{ }^{9}$

The application of equation (4) to the distance scores, obtained by employing equation (5), resulted in a new weighted index of human development which we called MHDIF2.

\footnotetext{
${ }^{8}$ The reader should note that as there is only one factor score the distance vector in equation (3) has only one element.

${ }^{9}$ Equation (5) is general for any number of factors and therefore may also be used for finding MHDIF1.
} 


\section{THE BORDA COMPOSITE INDEX}

One of the most frequently used composite indices for ranking a number of cases is the Borda rule. ${ }^{10}$ This index provides a ranking order on the basis of the sum of rankings by individual components. First countries are ranked according to each component. Then these ranks are added in order to find the composite scores. Countries are then ranked on the basis of their composite scores. We used the Borda rule for finding an alternative human development index and compared its results with other indices. We called this measure BORDA.

Table A3 in Appendix A presents the computed indices and their components. The original data and the HDI for 174 countries are taken from the HDR 1995.

\section{COMPARISON OF DIFFERENT MEASURES OF HUMAN DEVELOPMENT}

It is a useful exercise to compare the robustness of the indices discussed above. Table 2 presents the ranking order of 174 countries by these indices and their constituent components. This will allow us to compare the results and also investigate whether the HDI and other indices developed are redundant as claimed by some literature (McGillivray, 1991).

To investigate the relationships between these indices we first computed the Pearson (simple) correlation between the values of the indices. They are presented in Table 3.

Correlation coefficients presented in Table 3 are all significant at 1 per cent level. They reflect a remarkable degree of similarity between our indices and also their constituent components. They seem to support the suggestion that these indices as compared to each other, and more importantly in relation to their components, are redundant. That is any one of them can produce similar results.

In order to investigate these results further we computed the rank correlations between them. Table 4 presents the Spearman correlation coefficients for each pair of rankings by different indices.

All coefficients are statistically significant at 1 per cent and reveal high similarity between our measures. Again they confirm the redundancy of the indices considered with respect to their components.

A further inspection of Table 2 reveals that not all indices or components in all sections of this table produce the same results. To test the robustness of our indices it would be useful to look at sets of countries which are ranked best and worst in Table 2 and compare this set with the ranking results of other indices. ${ }^{11}$ The second column of Table 2 presents the ranking of countries by the MHDI. We will compare the results of ranking by other measures with those of the MHDI.

The top 15 countries, as ranked by the MHDI - from Canada down to Germany - appear in the same set when ranked by the HDI and MHDIF1 indicating a remarkable similarity in results by these indices for the best set of countries. The same is true for the BORDA index. However a number of best countries are missing when countries are ranked by the MHDIF2. These are: Canada, Netherlands,

\footnotetext{
${ }^{10}$ For an application of this rule see Dasgupta and Weale (1992).

${ }^{11}$ For an example of this approach see Dasgupta and Weale (1992).
} 
Table 2. Ranking of countries by different indices and their components. (For the full ranking results see Noorbakhsh (1996b).)

\begin{tabular}{|c|c|c|c|c|c|c|c|c|}
\hline Country & MHDI & HDI & MHDIF1 & MHDIF2 & BORDA & LE & AEA & AGDP \\
\hline Canada & 1 & 1 & 1 & 32 & 1 & 10 & 1 & 8 \\
\hline Netherlands & 2 & 4 & 3 & 25 & 6 & 11 & 4 & 20 \\
\hline Iceland & 3 & 6 & 4 & 18 & 7 & 3 & 12 & 21 \\
\hline Japan & 4 & 3 & 2 & 10 & 3 & 1 & 19 & 9 \\
\hline Spain & 5 & 9 & 12 & 30 & 14 & 6 & 8 & 29 \\
\hline Sweden & 6 & 10 & 6 & 11 & 8 & 4 & 15 & 17 \\
\hline Norway & 7 & 7 & 7 & 23 & 5 & 13 & 5 & 15 \\
\hline France & 8 & 8 & 8 & 22 & 4 & 14 & 6 & 11 \\
\hline Australia & 9 & 11 & 10 & 13 & 10 & 7 & 14 & 18 \\
\hline Switzerland & 10 & 13 & 9 & 8 & 9 & 5 & 29 & 2 \\
\hline USA & 11 & 2 & 5 & 27 & 2 & 21 & 3 & 1 \\
\hline Belgium & 12 & 12 & 13 & 19 & 11 & 16 & 9 & 14 \\
\hline Austria & 13 & 14 & 14 & 20 & 12 & 18 & 10 & 13 \\
\hline Finland & 14 & 5 & 11 & 33 & 15 & 23 & 2 & 24 \\
\hline Germany & 15 & 15 & 15 & 15 & 13 & 22 & 13 & 6 \\
\hline United Kingdom & 16 & 18 & 19 & 14 & 18 & 19 & 20 & 23 \\
\hline New Zealand & 17 & 17 & 20 & 28 & 17 & 26 & 7 & 26 \\
\hline Italy & 18 & 20 & 16 & 7 & 19 & 9 & 49 & 19 \\
\hline Denmark & 19 & 16 & 18 & 21 & 16 & 27 & 11 & 12 \\
\hline Israel & 20 & 21 & 22 & 12 & 22 & 15 & 40 & 27 \\
\hline Sri Lanka & 88 & 97 & 85 & 91 & 81 & 48 & 80 & 102 \\
\hline Kyrgyzstan & 89 & 89 & 83 & 99 & 77 & 86 & 33 & 103 \\
\hline Romania & 90 & 98 & 90 & 95 & 87 & 73 & 71 & 104 \\
\hline Algeria & 91 & 85 & 102 & 71 & 104 & 98 & 123 & 70 \\
\hline Armenia & 92 & 90 & 74 & 103 & 51 & 42 & 18 & 111 \\
\hline Turkmenistan & 93 & 86 & 91 & 96 & 78 & 110 & 27 & 89 \\
\hline Peru & 94 & 93 & 96 & 93 & 96 & 105 & 64 & 94 \\
\hline Georgia & 95 & 92 & 76 & 106 & 54 & 41 & 17 & 117 \\
\hline Uzbekistan & 96 & 94 & 86 & 102 & 74 & 82 & 28 & 106 \\
\hline Azerbaijan & 97 & 99 & 88 & 101 & 82 & 63 & 60 & 108 \\
\hline South Africa & 98 & 95 & 103 & 88 & 101 & 118 & 85 & 80 \\
\hline Lebanon & 99 & 101 & 98 & 105 & 94 & 88 & 62 & 110 \\
\hline Philippines & 100 & 100 & 100 & 108 & 92 & 104 & 44 & 109 \\
\hline Oman & 101 & 91 & 95 & 47 & 88 & 78 & 145 & 31 \\
\hline Tajikistan & 102 & 103 & 99 & 115 & 93 & 69 & 61 & 129 \\
\hline Samoa (Western) & 103 & 102 & 101 & 117 & 85 & 95 & 25 & 124 \\
\hline Chad & 161 & 162 & 161 & 162 & 162 & 159 & 149 & 160 \\
\hline Angola & 162 & 164 & 162 & 163 & 164 & 164 & 148 & 162 \\
\hline Burundi & 163 & 165 & 163 & 161 & 165 & 152 & 162 & 164 \\
\hline Guinea-Bissau & 164 & 163 & 164 & 165 & 163 & 172 & 144 & 156 \\
\hline Gambia & 165 & 161 & 165 & 164 & 160 & 169 & 158 & 139 \\
\hline Mozambique & 166 & 167 & 166 & 166 & 170 & 166 & 161 & 173 \\
\hline Ethiopia & 167 & 171 & 167 & 168 & 172 & 160 & 169 & 174 \\
\hline Guinea & 168 & 168 & 168 & 169 & 173 & 171 & 166 & 170 \\
\hline Somalia & 169 & 166 & 169 & 167 & 166 & 163 & 172 & 152 \\
\hline Mali & 170 & 172 & 170 & 171 & 174 & 167 & 171 & 171 \\
\hline Afghanistan & 171 & 170 & 172 & 172 & 171 & 173 & 170 & 158 \\
\hline Burkina Faso & 172 & 169 & 171 & 170 & 167 & 161 & 173 & 159 \\
\hline Sierra Leone & 173 & 173 & 173 & 173 & 168 & 174 & 168 & 153 \\
\hline Niger & 174 & 174 & 174 & 174 & 169 & 165 & 174 & 157 \\
\hline
\end{tabular}


Table 3. Correlation matrix for various measures of human development - all countries.

\begin{tabular}{lccccccc}
\hline & MHDI & HDI & MHDIF1 & MHDIF2 & BORDA & LE & AEA \\
\hline HDI & 0.992 & - & - & - & - & - & - \\
MHDIF1 & 0.997 & 0.991 & - & - & - & - & - \\
MHDIF2 & 0.979 & 0.975 & 0.971 & - & - & - & - \\
BORDA & 0.980 & 0.971 & 0.981 & 0.948 & - & - & - \\
LE & 0.952 & 0.945 & 0.962 & 0.926 & 0.940 & - & - \\
AEA & 0.889 & 0.886 & 0.905 & 0.799 & 0.865 & 0.837 & - \\
AGDP & 0.914 & 0.908 & 0.895 & 0.960 & 0.906 & 0.815 & 0.664 \\
\hline
\end{tabular}

Table 4. Rank correlation matrix for various measures of human developmentall countries.

\begin{tabular}{lccccccc}
\hline & MHDI & HDI & MHDIF1 & MHDIF2 & BORDA & LE & AEA \\
\hline HDI & 0.996 & - & - & - & - & - & - \\
MHDIF1 & 0.996 & 0.991 & - & - & - & - & - \\
MHDIF2 & 0.972 & 0.966 & 0.966 & - & - & - & - \\
BORDA & 0.982 & 0.982 & 0.991 & 0.943 & - & - & - \\
LE & 0.942 & 0.933 & 0.955 & 0.912 & 0.963 & - & - \\
AEA & 0.860 & 0.866 & 0.877 & 0.751 & 0.905 & 0.830 & - \\
AGDP & 0.943 & 0.947 & 0.934 & 0.976 & 0.918 & 0.859 & 0.714 \\
\hline
\end{tabular}

Iceland, Spain, Norway, France, USA, Belgium, Austria and Finland. These results throw doubt on the suitability of MHDIF2.

How does our best list compare with the ranking of countries by the individual components of MHDI? As far as the ranking by the LE is concerned USA, Belgium, Austria, Finland and Germany are missing from the top list. Ranking by AEA results in Japan and Switzerland not to be included in the top list of 15 countries. The effect of ranking countries by AGDP on our best list is remarkable. Netherlands, Iceland, Spain, Sweden, Australia and Finland are not included in the top 15 countries when ranked by AGDP. Amongst other things one may suggest that these results do not support the redundancy of the HDI (and those of the other indices) with respect to the income component.

The worst fifteen as ranked by the MHDI are at the end of Table 2, from Benin to Niger. All indices of human development produced similar results for this group. However when countries are ranked by the LE component Benin, Chad and Burundi are replaced by Rwanda, Malawi and Uganda in the worst list. This dissimilarity between results gets worse when we use AEA for ranking. There are striking differences in results when we rank countries by the income component. When ranked by the AGDP 8 out of 15 countries are replaced by other countries. For the worst list the results fail to support the proposition that ranking by the income component would result in the same order as that by, for example, the HDI. Table 5 summarizes the performance of various indices and components with respect to that of the MHDI.

Table 5 presents remarkable similarities between the results of MHDI, HDI MHDIF1 and BORDA indices. It also indicates that the use of MHDIF2 and the individual components would result in rather different ranking order. It seems that to a significant extent the ranking of those countries appearing in the middle section of 
Table 5. Comparison of ranking results of human development indices and components with the MHDI.

\begin{tabular}{llllllll}
\hline Set & HDI & MHDIF1 & MHDIF2 & BORDA & LE & AEA & AGDP \\
\hline $\begin{array}{lllll}\text { Best } \\
\text { Worst }\end{array}$ & $\begin{array}{l}\text { similar } \\
\text { similar }\end{array}$ & $\begin{array}{l}\text { similar } \\
\text { similar }\end{array}$ & $\begin{array}{l}\text { very different } \\
\text { similar }\end{array}$ & $\begin{array}{l}\text { similar } \\
\text { similar }\end{array}$ & $\begin{array}{l}\text { very different } \\
\text { different }\end{array}$ & $\begin{array}{l}\text { different } \\
\text { very different }\end{array}$ & $\begin{array}{l}\text { very different } \\
\text { very different }\end{array}$ \\
\hline
\end{tabular}

Table 2 are responsible for the high rank correlation amonst our indices and their components.

This qualitative assessment suggests that despite the high correlations and rank correlations between the indices and their components for the full sample, they may produce different results for various sections of the sample.

To investigate this further we needed to divide our full sample into a set of subsamples and see how these indices would perform for various groups of countries. More importantly we are interested to know whether our indices, with respect to their components, are redundant.

The following two separate grouping procedures were employed:

Equal size grouping scheme - We first divided the full sample in Table 2 into four groups, according to the MHDI ranking, of equal sizes (44, 44, 43 and 43 countries). One top group 2, middle groups and a bottom group. ${ }^{12}$

Grouping by heterogeneity in the level of the MHDI - The second criterion was based on the properties of the MHDI. An inspection of MHDI revealed that the value of this index drops significantly at certain levels. It was also noted that decreases beyond 0.015 does not occur very frequently in the index (see the last column in Table A3 in Appendix A). On the other hand we did not want to end up with groups of very small sizes as this would affect the outcome. We therefore set the minimum number of countries in a group to be 20 . Bearing in mind this minimum and the decrease in the MHDI above 0.015 as the break level we ended up with five groups of unequal sizes.

We then computed the rank correlation amongst our indices and their components for each of these groups separately.

\subsection{Statistical Results for Equal Size Grouping Scheme}

Table 6 presents the rank correlation coefficients between the human development indices and their components for four groups of equal sizes.

For group 1 (the top group) as indicated by their high correlation coefficients MHDI, HDI, MHDIF1 and BORDA produce similar rankings results while MHDIF2 seems to be out of line as compared with them. LE and AEA components have moderately high correlation with our indices but lower than those for the whole sample. However, AGDP is exhibiting much lower correlation with the indices, in

\footnotetext{
${ }^{12}$ Initially we used an additional grouping procedure by dividing the full sample in Table 2 into three groups of equal sizes ( 58 countries in each group) in order of their ranking by the MHDI - the top, middle and bottom groups. As the results of the statistical analysis for these groups were similar to those for the four groups scenario it was decided to limit the study to those groups mentioned in the text.
} 
Table 6. Rank correlation coefficients for the groups of equal sizes.

\begin{tabular}{|c|c|c|c|c|c|c|c|}
\hline & MHDI & HDI & MHDIF1 & MHDIF2 & BORDA & LE & AEA \\
\hline \multicolumn{8}{|l|}{ Group 1} \\
\hline HDI & 0.925 & - & - & - & - & - & - \\
\hline MHDIF1 & 0.981 & 0.914 & - & - & - & - & - \\
\hline MHDIF2 & 0.354 & $0.127^{*}$ & 0.444 & - & - & - & - \\
\hline BORDA & 0.954 & 0.956 & 0.960 & 0.312 & - & - & - \\
\hline LE & 0.820 & 0.770 & 0.813 & 0.380 & 0.768 & - & - \\
\hline AEA & 0.740 & 0.871 & 0.701 & $-0.188^{*}$ & 0.812 & 0.423 & - \\
\hline AGDP & 0.533 & 0.401 & 0.645 & 0.795 & 0.577 & 0.367 & $0.193^{*}$ \\
\hline \multicolumn{8}{|l|}{ Group 2} \\
\hline HDI & 0.946 & - & - & - & - & - & - \\
\hline MHDIF1 & 0.926 & 0.841 & - & - & - & - & - \\
\hline MHDIF2 & 0.728 & 0.692 & 0.578 & - & - & - & - \\
\hline BORDA & 0.645 & 0.591 & 0.820 & $0.097^{*}$ & - & - & - \\
\hline LE & $0.129^{*}$ & $-0.214^{*}$ & 0.371 & $-0.207^{*}$ & 0.598 & - & - \\
\hline AEA & $0.282^{*}$ & 0.326 & 0.438 & -0.357 & 0.772 & 0.270 & - \\
\hline AGDP & 0.722 & 0.706 & 0.572 & 0.978 & $0.105^{*}$ & -0.320 & $0.276^{*}$ \\
\hline \multicolumn{8}{|l|}{ Group 3} \\
\hline HDI & 0.948 & - & - & - & - & - & - \\
\hline MHDIF1 & 0.964 & 0.908 & - & - & - & - & - \\
\hline MHDIF2 & 0.768 & 0.826 & 0.651 & - & - & - & - \\
\hline BORDA & 0.943 & 0.946 & 0.961 & 0.691 & - & - & - \\
\hline LE & 0.798 & 0.678 & 0.852 & 0.535 & 0.770 & - & - \\
\hline AEA & 0.584 & 0.496 & 0.684 & $0.004^{*}$ & 0.655 & 0.440 & - \\
\hline AGDP & 0.430 & 0.610 & $0.280^{*}$ & 0.833 & $0.412^{*}$ & $0.073^{*}$ & $-0.235^{*}$ \\
\hline \multicolumn{8}{|l|}{ Group 4} \\
\hline HDI & 0.975 & - & - & - & - & - & - \\
\hline MHDIF1 & 0.996 & 0.971 & - & - & - & - & - \\
\hline MHDIF2 & 0.961 & 0.966 & 0.945 & - & - & - & - \\
\hline BORDA & 0.950 & 0.981 & 0.939 & 0.969 & - & - & - \\
\hline LE & 0.811 & 0.782 & 0.787 & 0.875 & 0.802 & - & - \\
\hline AEA & 0.715 & 0.659 & 0.730 & 0.570 & 0.602 & 0.307 & - \\
\hline AGDP & 0.435 & 0.569 & $0.403^{*}$ & 0.604 & 0.658 & 0.431 & $0.024^{*}$ \\
\hline
\end{tabular}

*Insignificant at $5 \%$ level.

particular with the HDI. It is interesting to note that the highest coefficient for AGDP is 0.795 , with MHDIF2, which is the out-of-line index.

This is throwing some doubt, at least for this group, on the idea that our indices, with reference to their components, are redundant. Furthermore, it is worth noting that the rank correlation coefficient between the components themselves are low or insignificant.

For group 2 once again there is a close association between MHDI, HDI and MHDIF1, while BORDA reflects a moderate correlation with the above indices. Interestingly for this section of the table the effect of LE and AEA on the indices drop dramatically and become insignificant in some cases. At the same time the AGDP's correlation coefficients with the MHDI and HDI pick up while its correlation with BORDA and other components become insignificant or negative. 
All indices for group 3 exhibit high correlation coefficients with each other, though those between the MHDIF2 and the rest are of lower magnitude. LE has now much higher correlations with the indices while the correlations between AEA and AGDP and the indices are moderately low with some being insignificant. The correlations amongst the components are also low or insignificant.

All indices are producing similar results for group 4 as indicated by high and significant correlations amongst them. Once again the correlation coefficients between LE and indices are high. The same, but to a lesser extent apply to AEA. Association between income and the indices are again low, and in one case insignificant. The correlations amongst the components are also low or insignificant.

Overall three of our measures (MHDI, HDI and MHDIF1) seem to be strikingly similar in terms of their results. The BORDA performs well in three groups but is slightly out of line in one group. The MHDIF2 produces similar results for one group, exhibits moderate similarity for two groups and it is out of line for the remaining group.

More importantly, the results indicate that there are not enough similarities in rankings by our indices and their individual components to conclude that MHDI, HDI and MHDIF1, with respect to their components, are redundant.

\subsection{Statistical Results for the Grouping by the Heterogeneous Levels of the MHDI}

Table 7 presents the rank correlation coefficients between the human development indices and their components for five groups, of various sizes, at different levels of human development.

Group 1 (High Human Development Countries) includes the first 23 countries in Table A3, from Canada to Hong Kong, with an average MHDI far above the overall mean of 0.583 (note that there is a drop of 0.015 from country 23 to 24). For this group MHDI, HDI, MHDIF1 and BORDA have high correlations with each other. Once again the MHDIF2 is totally out of line with the rest. The correlations amongst the components and indices are either moderate or insignificant providing evidence that our indices, with respect to their components (in particular the AGDP), are not redundant. All correlation coefficients amongst the components are insignificant.

Group 2 (High-Medium Human Development Countries) includes 39 countries in Table A3, from Barbados to Seychelles. For this group the correlation coefficient between MHDI and MHDIF1 is high while those for the rest of the indices are relatively lower. Different degrees of association between individual components and various indices are interesting. While income component has a moderate association with MHDI and MHDIF1 and in particular with MHDIF2 it has no significant association with HDI. There is little similarity between the rankings according to AEA and the indices. Once again the correlation coefficients between the components of the indices are either insignificant or low.

Group 3 (Average Human Development Countries) includes 38 countries in Table A3, from Bulgaria to Philippines. The highest correlation coefficient in this group is between MHDI and HDI. The insignificant correlation coefficients of these indices with the BORDA index are interesting. The latter seems to be out of line with the rest of the indices. Similarly the insignificant coefficients between LE and AEA on the one hand and MHDI and HDI on the other hand are notable. It is the AGDP 
Table 7. Rank correlation coefficients for groups at various levels of human development.

\begin{tabular}{|c|c|c|c|c|c|c|c|}
\hline & MHDI & HDI & MHDIF1 & MHDIF2 & BORDA & LE & AEA \\
\hline \multicolumn{8}{|l|}{ Group 1} \\
\hline HDI & 0.876 & - & - & - & - & - & - \\
\hline MHDIF1 & 0.917 & 0.912 & - & - & - & - & - \\
\hline MHDIF2 & $-0.301^{*}$ & -0.532 & $-0.196^{*}$ & - & - & - & - \\
\hline BORDA & 0.871 & 0.903 & 0.939 & $-0.294^{*}$ & - & - & - \\
\hline LE & 0.484 & $0.199^{*}$ & 0.517 & 0.531 & $0.311^{*}$ & - & - \\
\hline AEA & 0.578 & 0.777 & 0.547 & -0.868 & 0.637 & $-0.304^{*}$ & - \\
\hline AGDP & $0.263^{*}$ & $0.350^{*}$ & 0.509 & $0.191^{*}$ & 0.608 & $0.199^{*}$ & $0.154^{*}$ \\
\hline \multicolumn{8}{|l|}{ Group 2} \\
\hline HDI & 0.826 & - & - & - & - & - & - \\
\hline MHDIF1 & 0.974 & 0.770 & - & - & - & - & - \\
\hline MHDIF2 & 0.731 & $0.291^{*}$ & 0.791 & - & - & - & - \\
\hline BORDA & 0.882 & 0.883 & 0.892 & 0.500 & - & - & - \\
\hline LE & 0.706 & 0.593 & 0.723 & 0.521 & 0.741 & - & - \\
\hline AEA & $0.165^{*}$ & 0.566 & $0.122^{*}$ & -0.409 & 0.439 & $-0.041^{*}$ & - \\
\hline AGDP & 0.726 & $0.307^{*}$ & 0.785 & 0.949 & 0.517 & 0.352 & $-0.256^{*}$ \\
\hline \multicolumn{8}{|l|}{ Group 3} \\
\hline HDI & 0.921 & - & - & - & - & - & - \\
\hline MHDIF1 & 0.739 & 0.608 & - & - & - & - & - \\
\hline MHDIF2 & 0.733 & 0.773 & $0.209^{*}$ & - & - & - & - \\
\hline BORDA & $0.293^{*}$ & $0.178^{*}$ & 0.816 & -0.330 & - & - & - \\
\hline LE & $0.177^{*}$ & $-0.030^{*}$ & 0.620 & $-0.249^{*}$ & 0.778 & - & - \\
\hline AEA & $-0.204^{*}$ & $-0.205^{*}$ & 0.348 & -0.759 & 0.759 & 0.391 & \\
\hline AGDP & 0.676 & 0.781 & $0.130^{*}$ & 0.945 & -0.382 & -0.463 & -0.669 \\
\hline \multicolumn{8}{|l|}{ Group 4} \\
\hline HDI & 0.907 & - & - & - & - & - & - \\
\hline MHDIF1 & 0.963 & 0.862 & - & - & - & - & - \\
\hline MHDIF2 & 0.679 & 0.780 & 0.589 & - & - & - & - \\
\hline BORDA & 0.903 & 0.945 & 0.911 & 0.723 & - & - & - \\
\hline LE & 0.637 & 0.495 & 0.711 & 0.547 & 0.622 & - & - \\
\hline AEA & $0.322^{*}$ & $0.185^{*}$ & 0.425 & -0.370 & $0.286^{*}$ & $-0.004^{*}$ & - \\
\hline AGDP & 0.321 & 0.575 & $0.185^{*}$ & 0.808 & 0.461 & $0.010^{*}$ & -0.492 \\
\hline \multicolumn{8}{|l|}{ Group 5} \\
\hline HDI & 0.970 & - & - & - & - & - & - \\
\hline MHDIF1 & 0.995 & 0.964 & - & - & - & - & - \\
\hline MHDIF2 & 0.956 & 0.961 & 0.936 & - & - & - & - \\
\hline BORDA & 0.942 & 0.978 & 0.929 & 0.963 & - & - & - \\
\hline LE & 0.768 & 0.731 & 0.738 & 0.851 & 0.764 & - & - \\
\hline AEA & 0.759 & 0.704 & 0.781 & 0.609 & 0.643 & $0.294^{*}$ & - \\
\hline AGDP & 0.460 & 0.606 & 0.421 & 0.629 & 0.691 & 0.438 & $0.096^{*}$ \\
\hline
\end{tabular}

${ }^{*}$ Insignificant at $5 \%$ level.

component which is more associated with these indices than the other components for this group of countries, however, the negative, or insignificant, association of this component with the other two components is notable.

Group 4 (Average-Poor Human Development Countries) includes 34 countries in Table A3, from Oman to Madagascar. Once again the MHDI, HDI, MHDIF1 and 
BORDA are exhibiting close association for this group. The AEA seems to be the least associated component with these indices. The AGDP also has a low or insignificant correlation with the indices mentioned above. Again little evidence is provided for the redundancy of the human development indices as compared with the AGDP. The insignificant and negative coefficients between the components are noteworthy.

Group 5 (Very Poor Human Development Countries) consists of the last 40 countries in Table A3, from Pakistan to Niger. The correlation coefficients amongst the indices indicate a high degree of similarities between their ranking results for this group. The magnitude of the coefficients between AGDP and the indices of human development are moderate to low while those between the LE and AEA and the indices are to some extent higher. The degree of association between the components themselves are either insignificant or low for this group.

Overall, the MHDI, HDI and MHDIF1 produce similar rankings for all groups. The BORDA produces almost the same ranking results as the other indices for the upper two and the lower two groups but gives totally different ranking for the middle group. The MHDIF2 performs well for the last group with moderately similar ranking results for three groups and a totally different ranking for one group.

Again the results do not provide enough evidence to support the proposition that the MHDI, HDI and MHDIF1, with respect to their components are redundant.

\section{CONCLUSIONS}

Out of the five indices, constructed from the components of the HDI, three of them - MHDI, HDI and MHDIF1 - produce almost similar ranking results. There are also similarities between the BORDA ranking and the rankings by those mentioned above. However, the technical properties of these indices are different and it is possible that they may give different results for a higher number of components. The MHDI is more sophisticated in terms of allowing for the diminishing returns to income and educational attainment. It also has a more sound technical structure. Despite these it does not produce significantly different ranking results for the selected data. Does this mean that the HDI is good enough and there is no need for an alternative index? This would be a difficult conclusion to draw as one should evaluate an index also with reference to its components and structure. Furthermore if the answer to the above question is positive then one may suggest that the simplest of them all, the BORDA index, by the same token, would serve the purpose.

Similarities between the ranking results of MHDIF1 and the rankings by the HDI and MHDI suggest that the equal weighting of the components of these indices is not a serious problem as indicated by some researchers. We may also conclude that the proposed treatment of the income component in constructing the MHDI does not result in the dominance of the index by this component as implied by the UNDP approach.

All four indices mentioned above seem to have the desired properties of a good composite index. That is (i) their components are not highly correlated with each other and (ii) the index itself is not highly correlated with any of its individual components. We may, therefore, conclude that there is little evidence to support the suggestion that any of these indices, as compared with their components, is redundant. 


\section{REFERENCES}

Adelman, I. and Morris, C. T. (1967). Society, Politics and Economic Development. Baltimore: Johns Hopkins University Press.

Chenery, H. et al. (1976). Redistribution With Growth. Oxford: Oxford University Press.

Chenery, H. and Srinivasan, T. N. (1988). Handbook of Development Economics Volume I. Amsterdam: Elsevier Science Publishers.

Dasgupta, P. and Weale, M. (1992). On measuring the quality of life, World Development 20(1).

Desai, M. (1991). Human development: concept and measurement, European Economic Review 35.

Desai, M. (1993). Income and alternative measures of well-being. In Westendorff and Ghai Monitoring Social Progress in the 1990s, Avebury: UNRISD.

Drewnowski, J. and Scott, W. (1966). The level of living index. United Nations Research Institute for Social Development. Report No. 4. Geneva: United Nations.

Griffin, K. and Knight, J. (1990). Human Development and the International Development Strategy for the 1990s. London: Macmillan.

Haq, M. U. (1995). Reflections on Human Development. Oxford: Oxford University Press.

Hicks, N. and Streeten, P. (1979). Indicators of development: the search for a basic needs yardstick, World Development 7.

Hopkins, M. (1991). Human development revisited: a new UNDP report, World Development 19(10).

Kelly, A. C. (1991). The human development index: handle with care, Population and Development Review 17(2).

McGillivray, M. (1991). The human development index: yet another redundant composite development indicator? World Development 19(10).

McGillivray, M. and White, H. (1993). Measuring development? The UNDP's human development index, Journal of International Development 5(2), 183-192.

McGranahan, D. V. et al. (1972). Contents and measurements of socio-economic development. New York: Praeger

McGranahan, D. V., Pizarro, P. and Richard, C. (1985). Measurement and Analysis of SocioEconomic Development. Geneva: United Nations Research Institute for Social Development.

Morris, M. D. (1979). Measuring the Condition of the World's Poor: The Physical Quality of Life Index. New York: Pergamon.

Murray, J. L. (1993). 'Development data constraints and the human development index. In Westendorff and Ghai. Monitoring Social Progress in the 1990s. Avebury: UNRISD.

Noorbakhsh, F. (1976). Development, Quantitative Analysis of Development and Planning for Development. PhD Thesis. University of Birmingham, United Kingdom.

Noorbakhsh, F. (1996a). Some reflections on the UNDP's human development index. CDS Occasional Paper No. 17. Glasgow: Centre for Development Studies, University of Glasgow.

Noorbakhsh, F. (1996b). The human development indices: are they redundant? CDS Occasional Paper No. 20. Glasgow: Centre for Development Studies, University of Glasgow.

Pyatt, G. (1992). There is nothing wrong with the HDI, but ..., Coventry: University of Warwick. (Mimeo).

Rao, V. V. B. (1991). Human development report 1990: review and assessment, World Development 19(10).

Rummel, R. J. (1970). Applied Factor Analysis. Evanston: Northwestern University Press. Seers, D. (1972). What are we trying to measure? The Journal of Development Studies 8(3). 
Sen, A. (1984). Resources, Values and Development. Oxford: Basil Blackwell.

Sen, A. (1988). The concept of development. In Chenery and Srinivasan, Ch. 1.

Sen, A. (1990). Development as capability expansion. In Griffin and Knight, Ch. 2.

Smith, P. (1993). Measuring human development, Asian Economic Journal 7(1).

Srinivasan, T. N. (1994). Human development: a new paradigm or reinvention of the wheel? American Economic Review, Papers and Proceedings 84(2).

Streeten, P., Burki, J. S., Haq, M. U., Hicks, N. and Stewart, F. (1981). First Things First: Meeting Basic Human Needs in Developing Countries. New York: Oxford University Press.

Streeten, P. (1994). Human development: means and ends, American Economic Review, Papers and Proceedings 84(2).

Trabold-Nubler, H. (1991). The human development index - a new development indicator? Intereconomics, September/October.

United Nations (1954). Report on International Definition and Measurement of Standards and Levels of Living. New York: United Nations.

United Nations Economic and Social Council Commission for Social Development (1969). Social Policy and Planning in National Development Report of the Meeting of Experts on Social Policy and Planning, held in Stockholm from 1 to 10 September, 1969. Geneva: United Nations.

United Nations Development Programme (UNDP) (1995). Human Development Report 1995. Oxford: Oxford University Press. [Also the same publication for 1990 to 1994.]

United Nations Research Institute for Social Development (UNRISD) (1972). Contents and Measurement of Socio-economic Development. New York: Praeger Publishers.

Westerndorff, D. G. and Ghai, D. (1993). Monitoring Social Progress in the 1990s. Avebury: UNRISD.

\section{APPENDIX A}

Table A1. Suggested values for $\varepsilon_{i}$ and ranges for income intervals

\begin{tabular}{lcc}
\hline$\varepsilon_{i}$ & Range of $y$ & Elasticity \\
\hline 0 & $y \leqslant y^{*}$ & 1.0 \\
0.1 & $y^{*}<y \leqslant 1.5 y^{*}$ & 0.9 \\
0.2 & $1.5 y^{*}<y \leqslant 2.0 y^{*}$ & 0.8 \\
0.3 & $2.0 y^{*}<y \leqslant 2.5 y^{*}$ & 0.7 \\
0.4 & $2.5 y^{*}<y \leqslant 3.0 y^{*}$ & 0.6 \\
0.5 & $3.0 y^{*}<y \leqslant 3.5 y^{*}$ & 0.5 \\
0.6 & $3.5 y^{*}<y \leqslant 4.0 y^{*}$ & 0.4 \\
0.7 & $4.0 y^{*}<y \leqslant 4.5 y^{*}$ & 0.3 \\
0.8 & $4.5 y^{*}<y \leqslant 5.0 y^{*}$ & 0.2 \\
\hline
\end{tabular}


Table A2. Suggested ranges for adult literacy and combined enrolment ratio

\begin{tabular}{lccc}
\hline $\begin{array}{l}\text { Adult literacy range } \\
(\mathrm{AL}) \%\end{array}$ & $\begin{array}{c}\text { Combined enrolment } \\
\text { ratio (ER) }\end{array}$ & $x$ & $e^{x}$ \\
\hline $0<\mathrm{AL} \leqslant 40$ & $0<\mathrm{ER} \leqslant 40$ & 0 & 1.000 \\
$40<\mathrm{AL} \leqslant 50$ & $40<\mathrm{ER} \leqslant 50$ & -0.1 & 0.905 \\
$50<\mathrm{AL} \leqslant 60$ & $50<\mathrm{ER} \leqslant 60$ & -0.2 & 0.819 \\
$60<\mathrm{AL} \leqslant 70$ & $60<\mathrm{ER} \leqslant 70$ & -0.3 & 0.741 \\
$70<\mathrm{AL} \leqslant 80$ & $70<\mathrm{ER} \leqslant 80$ & -0.4 & 0.670 \\
$80<\mathrm{AL} \leqslant 90$ & $80<\mathrm{ER} \leqslant 90$ & -0.5 & 0.606 \\
$90<\mathrm{AL} \leqslant 100$ & $90<\mathrm{ER} \leqslant 100$ & -0.6 & 0.549 \\
\hline
\end{tabular}

Table A3. Indices for 174 countries in order of the ranking by MHDI. For the complete results see Noorbakhsh (1996b).

\begin{tabular}{lccllccccc}
\hline Country & MHDI & HDI & MHDIF1 & MHDIF2 & BORDA & LE & AEA & AGDP & $\begin{array}{c}\text { Decrease } \\
\text { in MHDI }\end{array}$ \\
& & & & & & & & & \\
\hline 1. Canada & 0.965 & 0.950 & 1 & 0.743 & 19 & 77.4 & 82.50 & 7785 & - \\
2. Netherlands & 0.958 & 0.936 & 0.984 & 0.754 & 35 & 77.4 & 80.27 & 7714 & 0.007 \\
3. Iceland & 0.957 & 0.933 & 0.984 & 0.763 & 36 & 78.2 & 78.87 & 7712 & 0.001 \\
23. Hong Kong & 0.910 & 0.905 & 0.960 & 0.798 & 79 & 78.6 & 73.63 & 7773 & 0.003 \\
24. Barbados & 0.895 & 0.900 & 0.915 & 0.732 & 103 & 75.6 & 76.57 & 6962 & 0.015 \\
25. Greece & 0.895 & 0.907 & 0.921 & 0.718 & 94 & 77.6 & 76.33 & 6635 & 0.001 \\
62. Seychelles & 0.728 & 0.810 & 0.743 & 0.646 & 218 & 71.0 & 65.53 & 5418 & 0.011 \\
63. Bulgaria & 0.712 & 0.796 & 0.747 & 0.562 & 199 & 71.2 & 73.53 & 4250 & 0.017 \\
64. Kazakhstan & 0.704 & 0.798 & 0.741 & 0.551 & 206 & 69.6 & 75.13 & 4270 & 0.008 \\
100. Philippines & 0.583 & 0.677 & 0.647 & 0.426 & 257 & 66.3 & 76.17 & 2550 & 0.011 \\
101. Oman & 0.564 & 0.715 & 0.665 & 0.676 & 254 & 69.6 & 42.18 & 7320 & 0.019 \\
102. Tajikistan & 0.561 & 0.643 & 0.648 & 0.400 & 259 & 70.2 & 74.87 & 1740 & 0.003 \\
134. Madagascar & 0.354 & 0.432 & 0.379 & 0.260 & 413 & 56.5 & 59.80 & 710 & 0.005 \\
135. Pakistan & 0.331 & 0.483 & 0.352 & 0.358 & 384 & 61.5 & 32.13 & 2890 & 0.023 \\
136. Comoros & 0.328 & 0.415 & 0.330 & 0.277 & 412 & 56.0 & 48.07 & 1350 & 0.003 \\
172. Burkina Faso & 0.046 & 0.228 & 0.044 & 0.066 & 493 & 47.4 & 17.93 & 810 & 0.001 \\
173. Sierra Leone & 0.027 & 0.221 & 0.022 & 0.034 & 495 & 39.0 & 28.47 & 880 & 0.018 \\
174. Niger & 0.004 & 0.207 & 0.006 & 0.033 & 496 & 46.5 & 12.93 & 820 & 0.024 \\
\hline
\end{tabular}

